\title{
Mechanism of the Lower Esophageal Sphincter Relaxation
}

\section{ACTION OF PROSTAGLANDIN $E_{1}$ AND THEOPHYLLINE}

\author{
RaJ K. Goyal and Satish Rattan \\ From the Gastroenterology Section, Department of Medicine, Baylor College of \\ Medicine, Houston, Texas 77025
}

A B STRACT The intravenous injection of prostaglandin $E_{1}\left(P \mathrm{PE}_{1}\right)$ causes a dose-dependent relaxation of the lower esophageal sphincter (LES) in the intact, lightly anesthetized opossum. The action of $\mathrm{PGE}_{1}$ is not inhibited by the drugs that produce muscarinic or nicotinic cholinergic antagonism or alpha and beta adrenergic antagonism in the doses that inhibited the action of respective agonists. Moreover, this action is not affected by exogenous gastrin pentapeptide. The action of PGE on the LES is mimicked by isoproterenol, theophylline ethylenediamine, and dibutyryl cyclic AMP. Both theophylline, a phosphodiesterase inhibitor, and isoproterenol, an adenyl cyclase stimulator, added to the action of $\mathrm{PGE}_{1}$. On the other hand, adenyl cyclase inhibitor nicotinic acid, as well as phosphodiesterase stimulator, imidazole inhibited its action. Further, both nicotinic acid and imidazole inhibited the degree of LES relaxation produced by esophageal distension. These studies suggest that intracellular cyclic AMP may act as the "second messenger" in the regulation of the lower esophageal sphincter relaxation.

\section{INTRODUCTION}

The lower esophageal sphincter (LES) ${ }^{1}$ relaxes in response to swallowing to allow the passage of an ingested bolus of food (1), but the mechanism of this relaxation is not well understood. We have found that prostaglandin $E_{1}(2)$ and theophylline are potent relaxants of the LES. Beta adrenergic stimulation has previously been reported to cause inhibition of the circular muscle

Received for publication 14 July 1972 and in revised form 30 October 1972.

${ }^{1}$ Abbreviations and trivial names used in this paper: cAMP, cyclic AMP; hexamethonium, hexamethylenebis (trimethylammonium chloride) ; isoproterenol, $d l-\beta$ - (3,4-dihydroxyphenyl)- $\alpha$-isopropylamino ethanol; LES, lower esophageal sphincter; phentolamine, $2-(N-(m$-hydroxyphenyl)-p-toluidinomethyl) imidazoline; propranolol, 1-(isopropylamino)-3-(1-naphthyloxy)-2-propanol hydrochloride; $P G E_{1}$, prostaglandin $E_{1}$; theophylline, 1-3-dimethylxanthine. from the lower esophagus (3) including the sphincteric zone (4). Prostaglandins of $\mathrm{E}$ type, theophylline and isoproterenol, have been shown to enhance cyclic AMP in many tissues (5). We present here indirect evidence in an in vivo system which suggests that PGE1, theophylline, and isoproterenol may produce LES relaxation by enhancing cyclic AMP in the lower esophageal sphincter.

\section{METHODS}

Studies were done in the opossum (Didelphis virginiana) because the lower part of the esophagus and the lower esophageal sphincter, like that of man, is composed of smooth muscle fibers (6). The animals weighed between 2 and $3.5 \mathrm{~kg}$ and were of either sex. The animals were anesthetized with intraperitoneal sodium pentobarbital, 50 $\mathrm{mg} / \mathrm{kg}$, and were strapped supine to the animal board. The LES pressure was continuously monitored with a waterfilled polyvinyl catheter. An assembly of three polyvinyl catheters (ID $=0.86 \mathrm{~mm}$ and $O D=1.17 \mathrm{~mm}$ ) glued together with tetrahydrofuran, and each with side opening $1 \mathrm{~cm}$ apart, was connected to three pressure transducers. The catheters were constantly perfused with bubble-free water at a rate of $4.6 \mathrm{ml} / \mathrm{h}$ with a constant infusion pump (Harvard Apparatus Co., Inc., Millis, Mass.). The catheter assembly was introduced through the animal's mouth so that all the openings recorded intragastric pressures. The assembly was then gradually withdrawn so that the proximal opening was in the body of the esophagus, the middle one recorded the highest pressure in the lower high pressure zone and the distal one measured intragastric pressures. In initial studies a catheter assembly with openings $\frac{1}{2} \mathrm{~cm}$ apart was used in order to evaluate the possibility of the movement of the LES in relation to recording opening. Movement of the catheter assembly would shift the high pressure zone in either the proximal or the distal lead. LES relaxation produced by $\mathrm{PGE}_{1}$ and other agents could not be related to such a shift in the high pressure zone.

Test substances were injected through an intravenous cannula as a single bolus or by a slow continuous infusion. In some experiments, dibutyryl cyclic AMP and acetylcholine were injected directly into the left gastric artery which supplies the lower esophagus through its esophageal branch (Fig. 1). 5-10 min of normal base-line pressure was recorded between injections. The LES pressures were measured at end inspiration. The peak change in the sphincter pressure produced after drug administration was 


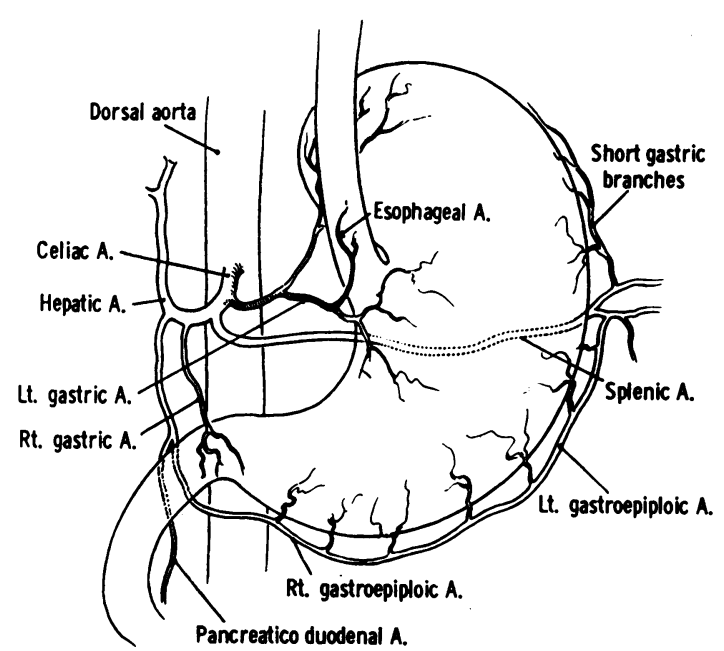

Figure 1 Arterial supply of the lower esophagus and the stomach in the opossum. This is a diagramatic representation of the branches of the celiac artery in one animal. Note the left gastric artery with its esophageal branch.

noted. To make the data uniform, change in sphincter pressure was expressed as a percent of the resting base line pressure just before the injection of the drug.

To study the effect of the agents in modifying the action of $\mathrm{PGE}_{1}$ the test agents were first injected and when the peak action had been reached, $\mathrm{PGE}_{1}(1 \mu \mathrm{g} / \mathrm{kg})$ was injected. The effect of $\mathrm{PGE}_{1}$ in these experiments was described as a percent change in the pressure obtained after the injection of other drugs.

The following drugs were used: phentolamine (Ciba Corp., Summit, N. J.), propranolol (Ayerst Laboratories, New York), atropine sulfate (Eli Lilly \& Co., Indianapolis, Ind.), hexamethonium (E. R. Squibb \& Sons, New York), norepinephrine (City Chemical Corp., New York), isoproterenol (Winthrop Laboratories, New York), acetylcholine (Sigma Chemical Co., St. Louis, Mo.), nicotine sulfate
(Sigma), pentagastrin (Ayerst), aminophylline (theophylline $85 \%$, ethylenediamine $15 \%$; International Medication Systems, South El Monte, Calif.), dibutyryl cyclic AMP (Schwarz/Mann Div., Orangeburg, N. Y.), nicotinic acid (ICN Nutritional Biochemicals Div., Cleveland, Ohio), imidazole (Eastman Organic Chemicals Div., Rochester, N. Y.) and prostaglandin $E_{1}$ (Upjohn Co., Kalamazoo, Mich.). A fresh solution of prostaglandin $E_{1}$ was prepared before each experiment by diluting the stock solution 500 times in $0.15 \mathrm{~N}$ saline. The stock solution contained $10 \mathrm{mg}$ of the prostaglandin powder in $1 \mathrm{ml}$ of $95 \%$ ethanol. Other agents were also diluted or dissolved in $0.15 \mathrm{~N}$ saline.

\section{RESULTS}

The reproducibility of the changes in the LES pressure in response to test agents was good. The mean coefficient of variation was $6.5 \%$ in the same animal and $6.3 \%$ in different animals, calculated for $\mathrm{PGE}_{1}$ in the dose of $1 \mu \mathrm{g} / \mathrm{kg}$.

Effect of prostaglandin $E_{1}$. Fig. 2 shows a representative response to a single intravenous injection of $P G E_{1}$. Injection of $0.19 \%$ ethanol (vehicle for $P_{G E}$ ) produced no effect. The effect of $\mathrm{PGE}_{1}$ was dose-dependent (Table I). The action, on an average, started in a minute after injection. The maximal action occurred with a dose of $2 \mu \mathrm{g} / \mathrm{kg}$. The duration of action varied from 1-17 min and was also dose related (Table I).

Prostaglandins of $E$ type cause a fall in arterial blood pressure. In four experiments the direct carotid blood pressure fell after $\mathrm{PGE}_{1}(1 \mu \mathrm{g} / \mathrm{kg})$ administration by $37-50 \mathrm{~mm} \mathrm{Hg}$ systolic and $24-47 \mathrm{~mm} \mathrm{Hg}$ diastolic. This hypotension alone was not responsible for the fall in LES pressure; a comparable degree of hypotension produced by blood letting in seven animals produced no significant change in LES pressure. ${ }^{2}$

\footnotetext{
${ }^{2}$ Goyal, R. K., and S. Rattan. Unpublished data.
}

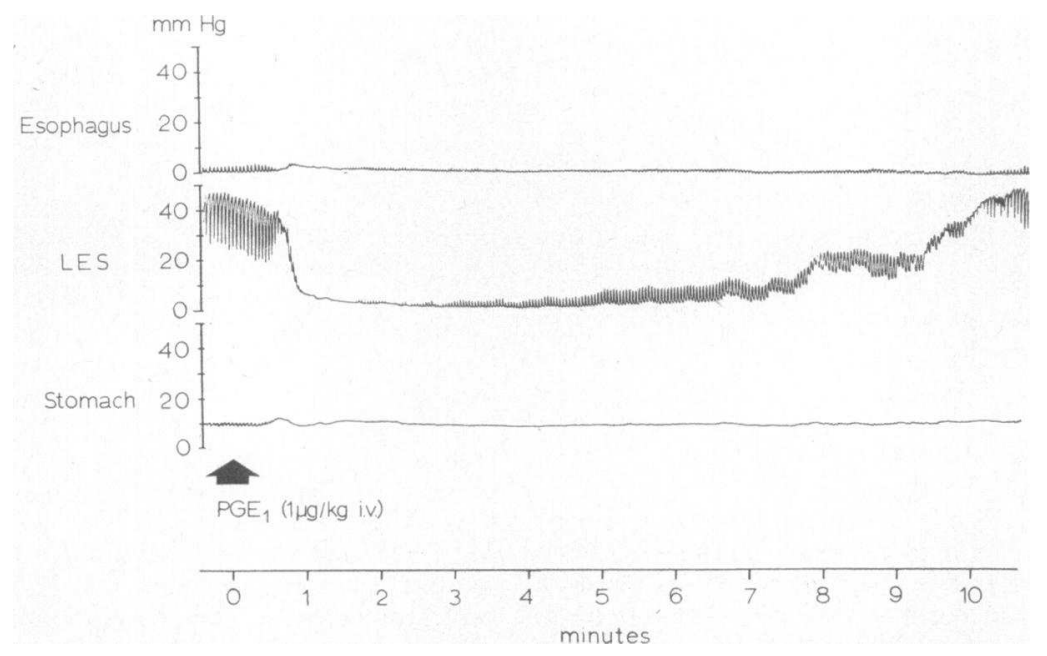

FIgURE 2 A representative response of the LES pressure to $\mathrm{PGE}_{1}$ administration. $\mathrm{PGE}_{1}$ was given i.v. as a single bolus (arrow). Note a prompt fall in LES pressure which lasted about $10 \mathrm{~min}$. There was no change in esophageal and gastric pressures. 
TABLE I

Effect of Prostaglandin $E_{1}$ on the LES Pressures

\begin{tabular}{cccccc}
\hline & $\begin{array}{c}\text { No. of } \\
\text { obser- } \\
\text { vations }\end{array}$ & $\begin{array}{c}\text { Resting } \\
\text { pressure* }\end{array}$ & $\begin{array}{c}\text { Fall in } \\
\text { pressure* }\end{array}$ & $\begin{array}{c}\text { Percent fall } \\
\text { in pressure* }\end{array}$ & $\begin{array}{c}\text { Duration } \\
\text { of action* }\end{array}$ \\
\hline$\mu g / k g$ & & $m m \mathbf{H g}$ & $m m$ Hg & & $\min$ \\
0.15 & 7 & $42.0 \pm 3.4$ & $2.1 \pm 1.8$ & $6.0 \pm 4.8$ & $1.5 \pm 0.5$ \\
0.25 & 7 & $48.4 \pm 7.1$ & $7.3 \pm 3.8$ & $15.4 \pm 7.8$ & $1.9 \pm 0.4$ \\
0.35 & 7 & $44.9 \pm 5.2$ & $20.1 \pm 7.2$ & $50.3 \pm 16.1$ & $5.7 \pm 2.1$ \\
0.5 & 11 & $41.7 \pm 3.3$ & $30.8 \pm 4.3$ & $74.6 \pm 9.1$ & $7.0 \pm 2.8$ \\
1 & 7 & $39.0 \pm 3.8$ & $34.3 \pm 4.8$ & $86.8 \pm 6.9$ & $9.2 \pm 1.7$ \\
2 & 9 & $48.7 \pm 4.0$ & $43.7 \pm 4.2$ & $88.1 \pm 3.6$ & $11.3 \pm 1.5$ \\
4 & 8 & $45.6 \pm 3.5$ & $40.6 \pm 4.6$ & $87.0 \pm 4.8$ & $11.3 \pm 0.9$ \\
8 & 7 & $43.1 \pm 6.5$ & $36.2 \pm 3.9$ & $85.6 \pm 7.6$ & $9.8 \pm 1.0$ \\
\hline
\end{tabular}

* Mean \pm SE.

Effect of neural antagonists. Information on the effect of different neural antagonists on the LES in the opossum in vivo was obtained. Alpha adrenergic antagonist phentolamine and muscarinic antagonist atropine caused a fall in sphincter pressure whereas beta adrenergic antagonist propranolol and nicotinic antagonist hexamethonium caused an increase (Table II).

Influence of the neural antagonists in modifying the action of $P G E_{1}$. The effect of $P G_{1}$ on the lower esophageal sphincter was not modified by various antagonists. The percent fall in the LES pressure mean $\pm \mathrm{SE}$ (five to seven observations each) after PGE $_{1}(1 \mu \mathrm{g} / \mathrm{kg}$ ) alone was $86.8 \pm 6.9 \%$ and $85.4 \pm 5.3,92 \pm 3.7,82.8 \pm 11.4$, and $84.6 \pm 6.3 \%$, respectively, after pretreatment with phentolamine, propranolol, atropine, and hexamethonium. These differences were not significant $(P>0.05)$.

Effect of $P G E_{1}$ on gastrin pentapeptide stimulated LES pressure. The interaction of $\mathrm{PGE}_{1}$ with exogenous gastrin pentapeptide for their action on the LES was investigated in five experiments. The mean LES pressure fall with $\mathrm{PGE}_{1}(2 \mu \mathrm{g} / \mathrm{kg})$ after gastrin pentapeptide $(1 \mu \mathrm{g} / \mathrm{kg}$ ) was $89.76 \% \pm 5.88(\mathrm{SE})$ as compared with $88.1 \% \pm 3.6$ with $\mathrm{PGE}_{1}$ alone $(P>0.05)$.

Effect of isoproterenol, theophylline, and dibutyryl cyclic $A M P$. The effect of isoproterenol and theophylline was tested because they are known to enhance cAMP levels in many tissues; isoproterenol acts by adenyl cyclase stimulation and theophylline by inhibiting phosphodiesterase (5). Both these agents produced a dose-dependent fall in the LES pressure (Fig. 3). Ethylenediamine, the vehicle for theophylline, caused no change in sphincter pressure. Dibutyryl cyclic AMP, a lipid soluble analogue of cAMP, when given intravenously had no effect on the sphincter pressure up to a dose of $15 \mathrm{mg} / \mathrm{kg}$. However, upon injection directly into the arterial supply of the LES from the left gastric artery, it produced a dose-dependent fall in LES pressure; the mean $\pm S E$ percent fall in LES pressure was
TABLE II

Effect of Various Neural Blocking Agents on the LES Pressure In Vivo*

\begin{tabular}{cccc}
\hline Test agent & $\begin{array}{c}\text { No. of } \\
\text { obser- } \\
\text { vations }\end{array}$ & $\begin{array}{c}\text { Percent change } \\
\text { in LES } \\
\text { pressure } \\
\text { (mean } \pm \mathrm{SE})\end{array}$ & Remarks \\
\hline $\begin{array}{c}\text { Phentolamine } \\
(1 \mathrm{mg} / \mathrm{kg})\end{array}$ & 6 & $\downarrow 34.8 \pm 4$ & $\begin{array}{c}\text { Antagonized the action } \\
\text { of norepinephrine } \\
(3 \mu \mathrm{g} / \mathrm{kg})\end{array}$ \\
$\begin{array}{c}\text { Propranolol } \\
(1 \mathrm{mg} / \mathrm{kg})\end{array}$ & 7 & $\uparrow 29.4 \pm 8$ & $\begin{array}{c}\text { Antagonized the action } \\
\text { of isoproterenol } \\
(5 \mu \mathrm{kg})\end{array}$ \\
$\begin{array}{c}\text { Atropine sulfate } \\
(1 \mathrm{mg} / \mathrm{kg})\end{array}$ & 5 & $\downarrow 24.0 \pm 8$ & $\begin{array}{c}\text { Antagonized the action } \\
\text { of intra-arterial } \\
\text { acetylcholine } \\
(10 \mu \mathrm{g} / \mathrm{kg})\end{array}$ \\
$\begin{array}{c}\text { Hexamethonium } \\
(10 \mathrm{mg} / \mathrm{kg})\end{array}$ & 6 & $\uparrow 29.0 \pm 17$ & $\begin{array}{c}\text { Antagonized the action } \\
\text { of nicotine sulfate } \\
(50 \mu \mathrm{kg})\end{array}$ \\
\hline
\end{tabular}

* The drugs were injected intravenously except acetylcholine which was injected intra-arterially in the LES.

$48.2 \pm 6.6,77.4 \pm 1.8$, and $85.4 \pm 4.5$, respectively, with the doses of 10,20 , and $30 \mu \mathrm{g} / \mathrm{kg}$.

Interaction of $P G E_{1}$ with agents that modify adenyl cyclase or phosphodiesterase activity. As summarized in Fig. 4, nicotinic acid, an inhibitor of adenyl cyclase (7) inhibited the action of $\mathrm{PGE}_{1}$ in a dose that did not alter the sphincter pressure. Imidazole, a stimulator of phosphodiesterase (8) also attenuated the action of $P G E_{1}$. On the other hand, isoproterenol and theophylline both added to the action of $\mathrm{PGE}_{1}$.

Effect of nicotinic acid and imidazole on the physiologically induced relaxation of the LES. In order to investigate the influence of adenyl cyclase inhibition or phosphodiesterase stimulation on LES relaxation produced by physiological stimuli, we quantitated the degree of LES relaxation in response to esophageal distension by injecting $2 \mathrm{ml}$ of air in the upper esophagus

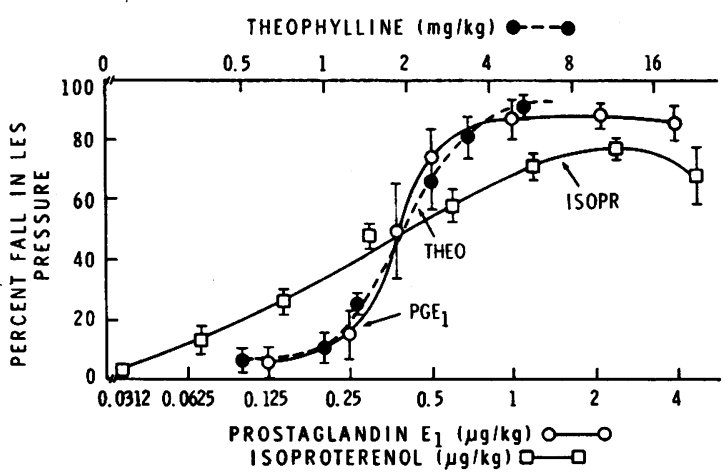

FIGURE 3 Dose-response curves of the effect of theophylline, isoproterenol, and $\mathrm{PGE}_{1}$ on the LES pressure. The doses are shown on a log scale. Each point represents a mean of 5-11 experiments $\pm 1 \mathrm{SE}$. 


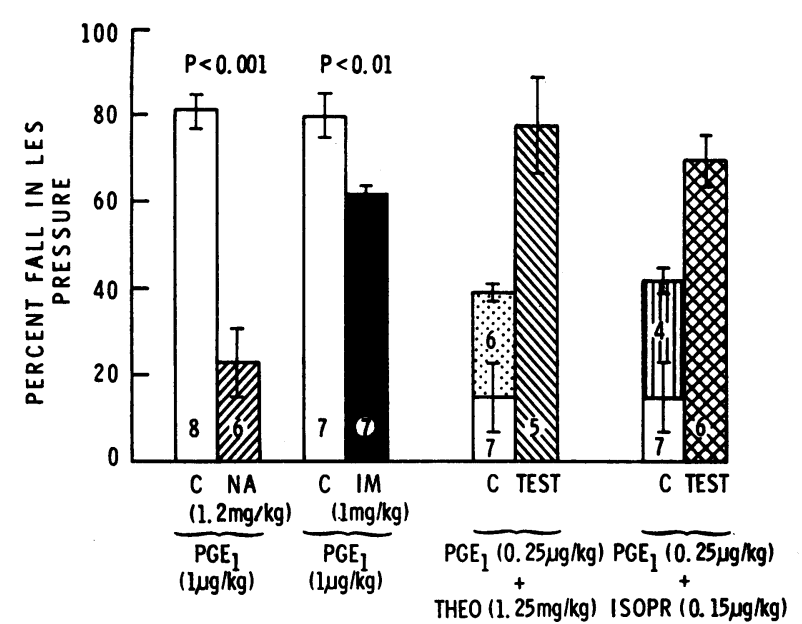

FIGURE 4 Interaction of $\mathrm{PGE}_{1}$ with agents that modify adenyl cyclase or phosphodiesterase activity. Bar height represents the fall in LES pressure with \pm 1 SE. The numbers in the bars indicate the number of experiments. Note a significant inhibition of $\mathrm{PGE}_{1}$ response after nicotinic acid (NA) and imidazole (IM) over control study with $\mathrm{PGE}_{1}$ alone $(\mathrm{C})$. The additive effect of $\mathrm{PGE}_{1}$ and theophylline (Theo) and $\mathrm{PGE}_{1}$ and isoproterenol (Isopr) when tested separately is shown over (C). The (test) indicates the additive effect obtained when the drugs were injected together.

during the intravenous infusion of nicotinic acid (1 $\mathrm{mg} / \mathrm{kg}$ per $\mathrm{min}$ ) and imidazole $(1 \mathrm{mg} / \mathrm{kg}$ per $\mathrm{min}$ ) and during the control period of saline infusion. The mean percent relaxation of the LES was $88.7 \pm 2.9 \mathrm{SE}(n=$ 9) during the control period as compared to $72.8 \pm 2.8$ $\mathrm{SE}(n=17)$ during the infusion of nicotinic acid. This difference was statistically significant $(P<0.01)$. A similar reduction in the degree of relaxation was found with imidazole. The LES relaxation was reduced from mean \pm SE $91.1 \% \pm 0.7(n=12)$ in control period to $77.4 \% \pm 2.4(n=9)$ during imidazole infusion. This difference was also significant $(P<0.01)$.

\section{DISCUSSION}

These studies reveal a very potent action of $P_{G E}$ in causing LES relaxation. The relaxant action of $\mathrm{PGE}_{1}$ is not modified by neural antagonists indicating its action directly on the sphincter muscle.

The action of the $\mathrm{PGE}_{1}$ may be due to its action on adenyl cyclase stimulation causing increase in intracellular cyclic AMP. PGE 1 has been shown to promote cyclic AMP levels in many tissues (5). We investigated the effects of some unrelated agents that also act to cause increase in cAMP levels such as isoproterenol and theophylline; they both produced dose-dependent relaxation of the LES. Moreover, dibutyryl cyclic AMP also produced similar effect. These evidences are further supported by $(a)$ additive response to the action of PGE 1 by isoproterenol and theophylline and $(b)$ in- hibition of $\mathrm{PGE}_{1}$ action by nicotinic acid and imidazole which inhibit cAMP synthesis and enhance cAMP breakdown, respectively. Furthermore, cyclic AMP related relaxation has been shown to occur in other smooth muscles of the body. Triner et al. (9) have shown that increase in the levels of cAMP caused by different agents produces relaxation of the smooth muscle from the rat uterus and arteries in vitro; the biochemical and functional effects were found to be dose-dependent and quantitatively correlated.

The body of the esophagus showed no change in response to these agents. This may be due to the fact that in the absence of background resting pressure, inhibition of activity is difficult to evaluate. Bennett and Fleshler (10) have recently reviewed the actions of prostaglandins on the gastrointestinal tract. $\mathrm{PGE}_{1}$ was found to cause relaxation of the circular muscles of the different organs. Our study suggests that the inhibition of the sphincter pressure may be an active, closely controlled and graded process although withdrawal of the action of excitatory agents such as gastrin may also lead to inhibition of the sphincter pressure (11).

The inhibition of the physiologically induced relaxation of the LES in our studies with agents which inhibit tissue cyclic AMP indicates that cyclic AMP mechanism may also be involved in the sphincter relaxation under physiological conditions.

The neurohormonal pathway responsible for LES relaxation is not well understood. There is some evidence to suggest that certain inhibitory nerves may be involved in the inhibition of gut muscle (12) including the LES (13). Burnstock, Campbell, Satchell, and Smythe (12) have suggested that adenosine triphosphate or a related nucleotide may be a neurotransmitter of these inhibitory nerves. ATP has been known to cause relaxation of the smooth muscles $(12,14)$. It is of interest because ATP is substrate for adenyl cyclase and this agent has been shown to inhibit phosphodiesterase (15), thus increasing tissue cAMP.

In human achalasia, there is impairment of lower esophageal sphincter relaxation but the genesis of this disorder is not well defined. The muscle strips from the lower esophageal sphincter in patients without achalasia have beta adrenergic receptors which are inhibitory (4). Further, it has been suggested that the patients with achalasia have defective beta adrenergic innervation of their lower esophageal sphincter muscle (4). Beta adrenergic stimulation seems to operate via the cyclic AMP mechanism. This is consistent with the concept that cyclic AMP may also be involved in the human LES relaxation. The results of our studies further suggest that agents such as $\mathrm{PGE}_{1}$ and theophylline or their analogues which promote cyclic AMP by acting on 
alternate mechanisms may provide the basis for drug treatment of achalasia.

\section{ACKNOWLEDGMENTS}

We thank Doctors Harold Brown, Norman Fleischer, and Thomas Burks for their helpful suggestions, and Dr. John Pike of the Upjohn Company for the gift of the prostaglandin.

This work was supported in part by a grant from the Kelsey and Leary Foundation, Houston, Tex.

\section{REFERENCES}

1. Code, C. F., and J. F. Schlegel. 1968. Motor action of the esophagus and its sphincters. Handb. Physiol. 1 (Sect. 6) : 1821.

2. Rattan, S., T. Hersh, and R. K. Goyal. 1971. Effects of prostaglandins on the lower esophageal sphincter. Clin. Res. 19: 660. (Abstr.)

3. Christensen, J., and E. E. Daniel. 1968. Effects of some autonomic drugs on circular esophageal smooth muscle. J. Pharmacol. Exp. Ther. 159: 243.

4. Misiewicz, J. J., S. L. Waller, P. P. Anthony, and J. W. P. Gummer. 1969. Achalasia of the cardia: pharmacology and histopathology of isolated cardiac sphincteric muscle from patients with and without achalasia. Q.J. Med. $38: 17$.

5. Robison, G. A., R. W. Butcher, and E. W. Sutherland. 1971. Cyclic AMP. Academic Press, Inc., New York.

6. Christensen, J., and G. F. Lund. 1969. Esophageal responses to distension and electrical stimulation. J. Clin. Invest. 48: 408 .

7. Skidmore, I. F., P. S. Schönhöfer, and D. Kritchevsky. 1971. Effects of nicotinic acid and some of its homo- logues on lipolysis, adenyl cyclase, phosphodiesterase and cyclic AMP accumulation in isolated fat cells. Pharmacology. 6: 330 .

8. Kukovetz, W. R., and G. Pöch. 1967. The action of imidazole on the effects of methylxanthines and catecholamines on cardiac contraction and phosphorylase activity. J. Pharmacol. Exp. Ther. 156: 514.

9. Triner, L., G. G. Nahas, Y. Vulliemoz, N. I. A. Overweg, M. Verosky, D. V. Habif, and S. H. Ngai. 1971. Cyclic AMP and smooth muscle function. Ann. N. Y. Acad. Sci. 185 : 458.

10. Bennett, A., and B. Fleshler. 1970. Prostaglandins and the gastrointestinal tract. Gastroenterology. 59: 790.

11. Lipshutz, W., W. Hughes, and S. Cohen. 1972. The genesis of lower esophageal sphincter pressure: its identification through the use of gastrin antiserum. $J$. Clin. Invest. $51: 522$.

12. Burnstock, G., G. Campbell, D. Satchell, and A. Smythe. 1970. Evidence that adenosine triphosphate or a related nucleotide is the transmitter substance released by nonadrenergic inhibitory nerves in the gut. Br. J. Pharmacol. $40: 668$.

13. Tuch, A., and S. Cohen. 1972. Neurogenic basis of lower esophageal sphincter relaxation. Clin. Res. 20: 467. (Abstr.)

14. Axelsson, J., and B. Holmberg. 1969. The effects of extracellularly applied ATP and related compounds on electrical and mechanical activity of the smooth muscle taenia coli from the guinea pig. Acta Physiol. Scand. 75: 149 .

15. Cheung, W. Y. 1967. Properties of cyclic $3^{\prime}, 5^{\prime}$-nucleotide phosphodiesterase from rat brain. Biochemistry. 6 :
1079 . 